\title{
Hemostatic and Fibrinolytic Response to Nasal Desmopressin in Hemodialysis Patients
}

\author{
Sukru Ulusoy Ercument Ovali Fazil Aydin Cihangir Erem Feyyaz Ozdemir \\ Kubra Kaynar
}

Department of Internal Medicine, Faculty of Medicine, Karadeniz Technical University, Trabzon, Turkey

\section{Key Words}

Nasal desmopressin · Hemodialysis patients .

Hemostasis

\begin{abstract}
Objective: To evaluate the effect of desmopressin (DDAVP) on hemostatic parameters during dialysis and in the interval between dialysis sessions. Subjects and Methods: Fifteen patients dialyzed twice weekly at least for 1 year and 15 healthy volunteers serving as a control group were enrolled in the study. Bleeding time, platelet count, prothrombin time, activated partial thromboplastin time, tissue plasminogen activator (tPA), plasminogen activator inhibitor (PAI-1), euglobulin clot lysis time, protein $\mathrm{C}$, protein $\mathrm{S}$, fibrinogen, D-dimer, factor $\mathrm{V}, \mathrm{VII}$, VIII, IX, $X$ and von Willebrand factor (VWF) values were studied at the beginning, at 2 and $4 \mathrm{~h}$ of dialysis with and without administration of DDAVP at a dose level of $2 \mu \mathrm{g} /$ $\mathrm{kg}$ intranasally. Results: After dialysis, bleeding time shortened, PAI-1 and fibrinogen levels were lower, while VWF and D-dimer levels were higher. After DDAVP administration, bleeding time, PAI-1 levels were significantly lower $(p<0.01)$, while tPA, factor VIII and VWF levels increased significantly $(p<0.001)$. Conclusion: The findings indicate that DDAVP can be used for patients on dialysis with serious bleeding.
\end{abstract}

Copyright (c) 2004 S. Karger AG, Basel

\section{Introduction}

Frequently, there is a tendency for bleeding to occur in the later periods of chronic renal failure (CRF); especially gastrointestinal and intracranial bleeding may be serious in some of these patients [1,2]. Although modern therapeutic methods for the treatment of uremia can reduce serious bleeding episodes significantly, bleeding is still one of the basic problems. Dialysis does not improve platelet dysfunction completely [3]. Recently some studies have shown that desmopressin (DDAVP) could be used in bleeding patients with CRF [4, 5] during hemodialysis because DDAVP reduces the level of protein $\mathrm{C}$ [6], increases the level of factor VIII and von Willebrand factor (VWF), while DDAVP raises tissue plasminogen activator (tPA) and lowers tissue plasminogen activator inhibitor (PAI-1) [7, 8]. Few studies have been done on the administration of DDAVP to patients on chronic hemodialysis treatment, involving hemostatic parameters [4].

In this study, we have assessed the effect of nasal DDAVP on hemostatic parameters of patients on chronic hemodialysis treatment, during and in the interval between dialysis sessions.

\begin{tabular}{ll}
\hline KARGER & ( ) 2004 S. Karger AG, Basel \\
Fax +4161306 1234 & \\
$\begin{array}{l}\text { E-Mail karger@karger.ch } \\
\text { www.karger.com }\end{array}$ & $\begin{array}{l}\text { Accessible online at: } \\
\text { www.karger.com/mpp }\end{array}$
\end{tabular}

Doç. Dr. Sukru Ulusoy

Karadeniz Teknik Üniversitesi, Tıp Fakültesi

İç Hastalıkları ABD

TR-61080 Trabzon (Turkey)

Tel. +90 46237754 54, Fax +90 46237756 69, E-Mail kkaynar@yahoo.com 
Table 1. Hematologic findings of patients with CRF and a healthy control group

\begin{tabular}{lcccl}
\hline Parameters & Normal ranges & 1Patients & 1Controls & p value \\
\hline Bleeding time, min & $2-5$ & $5.8 \pm 1.9$ & $4.0 \pm 0.5$ & $<0.01$ \\
Platelet, $\times 10^{9}$ & $1.5-4.0$ & $2.0 \pm 0.6$ & $2.7 \pm 0.3$ & $<0.001$ \\
PT, s & $10-14$ & $13.40 \pm 0.6$ & $13.53 \pm 0.8$ & NS \\
aPTT, s & $26-40$ & $30.7 \pm 5.5$ & $28.5 \pm 2.2$ & NS \\
tPA, ng/ml & $3-10$ & $10.0 \pm 4.3$ & $9.2 \pm 2.5$ & NS \\
PAI-1, ng/ml & $4-43$ & $35.57 \pm 5.18$ & $44.14 \pm 10.79$ & $<0.01$ \\
ECLT, min & $90-240$ & $225.3 \pm 44.0$ & $201.4 \pm 29.8$ & NS \\
Protein C, IU/ml & $0.59-1.37$ & $1.14 \pm 0.36$ & $1.45 \pm 0.41$ & $<0.05$ \\
Protein S, \% & $73-151$ & $87 \pm 27$ & $114 \pm 12$ & $<0.01$ \\
Fibrinogen, mg/dl & $160-350$ & $626.2 \pm 200.3$ & $391.2 \pm 97.0$ & $<0.05$ \\
D-dimer, $\mu$ g/ml & $0.0-0.5$ & $0.32 \pm 0.17$ & $0.37 \pm 0.16$ & NS \\
Factor V, \% & $40-150$ & $36 \pm 15$ & $65 \pm 22$ & $<0.001$ \\
Factor VII, \% & $40-150$ & $98 \pm 34$ & $151 \pm 47$ & $<0.01$ \\
Factor VIII, \% & $40-150$ & $71 \pm 12$ & $77 \pm 5$ & NS \\
VWF, \% & $40-150$ & $88 \pm 3$ & $83 \pm 11$ & NS \\
Factor IX, \% & $40-150$ & $62 \pm 55$ & $60 \pm 11$ & NS \\
Factor X, \% & $40-150$ & $119 \pm 29$ & $122 \pm 23$ & NS \\
\hline
\end{tabular}

NS $=$ Nonsignificant. Results are given as means \pm SD.

\section{Subjects and Methods}

Fifteen patients ( 9 men and 6 women) dialyzed with bicarbonate dialysate twice weekly at least for 1 year and 15 healthy volunteers (10 men and 5 women) as control were included in this study. No significant bleeding episodes were present in the patients' follow-up. Patients were given a loading dose of 1,000 U of heparin at the beginning and $500 \mathrm{U}$ per hour during dialysis.

Average age was $45 \pm 13$ and $48 \pm 8$ years in CRF and controls, respectively. The patients did not receive anticoagulant or antiaggregant agents except heparin during dialysis. In the first stage of the study, blood samples (as 1/10 ratio citrated blood) were taken from both groups, bleeding time was measured using Duke's method, platelet count, prothrombin time (PT), activated partial thromboplastin time (aPTT), tPA, PAI-1, euglobulin clot lysis time (ECLT), protein C, protein S, fibrinogen, D-dimer, factor V, VII, VIII, IX, $\mathrm{X}$ and VWF values were also measured.

In the second stage, at the onset of hemodialysis, at 2 and $4 \mathrm{~h}$ the same parameters were measured again in the study group. In the third stage, the patients received $2 \mu \mathrm{g} / \mathrm{kg}$ Ferrin AB 'Minirin' nasal spray (DDAVP) intranasally at the beginning of the dialysis session and the same parameters were remeasured. No atrophy of the nasal mucosa was observed in patient and control groups. In the last stage, the patients received $2 \mu \mathrm{g} / \mathrm{kg}$ DDAVP in the intervals between the dialysis sessions ( $36 \mathrm{~h}$ after dialysis) and the same parameters were measured $4 \mathrm{~h}$ later. The kits used were Organon Simplastin excel kit for PT, Organon Automated kit with coagulometer for aPTT, Biopool tint ELISA tPA kit for tPA, Biopool Spectrolyse/PL PAI kit (by chromogenic method) for PAI-1, Organon Fibriquik kit (by coagulometric method) for fibrinogen level, Biopool Minutex ${ }^{\mathrm{TM}}$ D-dimer kit for D-dimer calculation, Stage Asserachrom VWF kit for VWF (by ELISA method). Protein C and $\mathrm{S}$ were measured by ELISA method, factor levels were measured by coagulometric method with an Organon factor-deficient kit.
Statistical analysis between the two groups was compared using Student's t test (for small samples); Wilcoxon Rank Order test was used in the study group. Results were given as means $\pm \mathrm{SD}$, and $\mathrm{p}<0.05$ was considered statistically significant.

\section{Results}

Significant clinical bleeding or thrombotic episodes were not observed in the patients. The baseline hemostatic parameters of both study and control groups are given in table 1.

Bleeding time in the study group was significantly longer $(p<0.01)$ than that of controls. Platelet counts were lower $(p<0.01)$ but fibrinogen was higher $(p<0.05)$ in the study group than in the controls. In addition, protein $\mathrm{C}$ $(p<0.05)$, protein $S(p<0.01)$, PAI-1 $(p<0.01)$, factor V $(p<0.001)$ and factor VII $(p<0.01)$ levels were also significantly lower in the study group than the control group. There was no significant difference in other hemostatic parameters of both study and control groups (table 1).

The hemostatic parameters for the second part of the study, evaluated at the beginning, at 2 and $4 \mathrm{~h}$ of dialysis are given in table 2 . Bleeding time was significantly shorter $(p<0.05) 4 \mathrm{~h}$ of dialysis than at the beginning. The aPTT values were longer after $4 \mathrm{~h}$ of dialysis $(\mathrm{p}<0.001)$. However, the level of PAI-1 was shorter at $4 \mathrm{~h}$ of dialysis $(p<0.05)$. Fibrinogen levels were lower $(p<0.05)$, whereas VWF $(\mathrm{p}<0.05)$ and D-dimer levels were higher $(\mathrm{p}<$ 


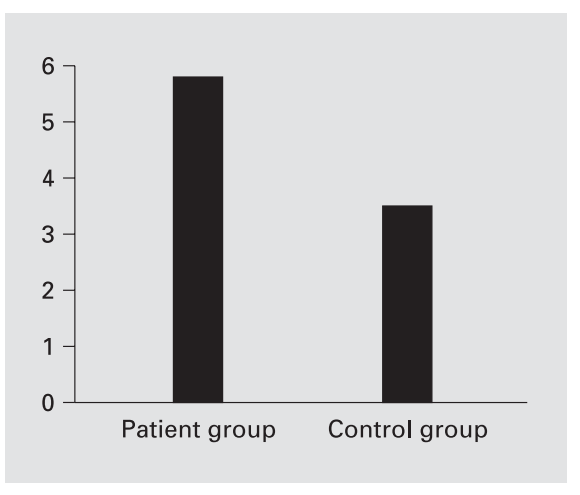

Fig. 1. Bleeding time of patient group and healthy control group.

Table 2. Hematologic findings in patients with CRF during hemodialysis

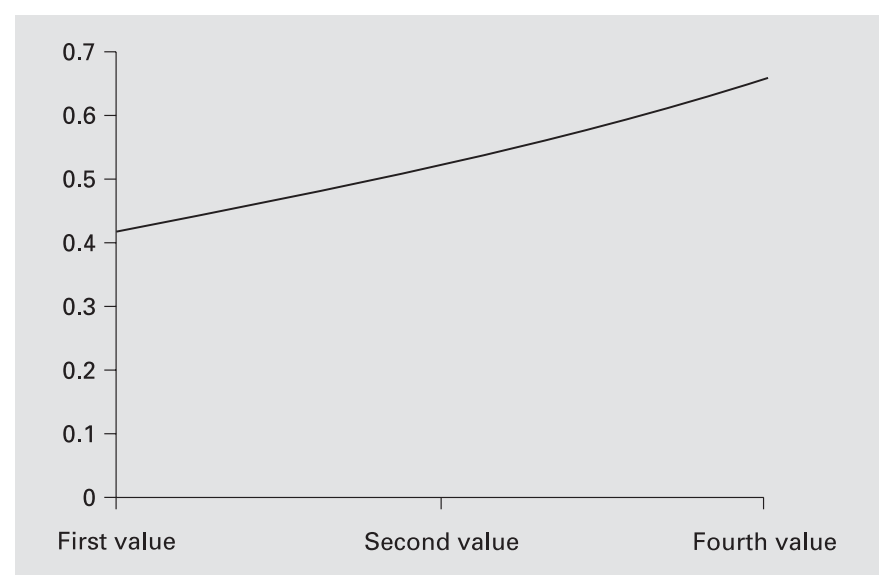

Fig. 2. D-dimer levels of patient group during hemodialysis.

\begin{tabular}{lcccl}
\hline & $1 \mathrm{~A} 1$ & $1 \mathrm{~A} 2$ & $1 \mathrm{~A} 3$ & $\mathrm{~A} 1-\mathrm{A} 3$ \\
\hline Bleeding time, min & $6.00 \pm 2.14$ & $4.28 \pm 1.12$ & $4.67 \pm 1.61$ & $\mathrm{p}<0.05$ \\
Platelet count, $\times 10^{9}$ & $2.0 \pm 0.7$ & $2.0 \pm 0.7$ & $2.0 \pm 0.8$ & $\mathrm{NS}$ \\
PT, s & $13.50 \pm 1.32$ & $14.21 \pm 0.84$ & $14.62 \pm 1.57$ & $\mathrm{NS}$ \\
$\mathrm{aPTT}, \mathrm{s}$ & $30.50 \pm 2.82$ & $100.55 \pm 44.12$ & $102.52 \pm 40.98$ & $\mathrm{p}<0.001$ \\
tPA, ng/ml & $12.53 \pm 5.45$ & $15.67 \pm 6.70$ & $12.89 \pm 5.33$ & $\mathrm{NS}$ \\
PAI-1, ng/ml & $32.50 \pm 7.00$ & $26.35 \pm 6.88$ & $25.28 \pm 6.86$ & $\mathrm{p}<0.05$ \\
ECLT, min & $184.28 \pm 59.28$ & $181.07 \pm 56.06$ & $181.07 \pm 42.70$ & $\mathrm{NS}$ \\
Protein C, IU/ml & $1.00 \pm 0.25$ & $1.07 \pm 0.21$ & $1.05 \pm 0.25$ & $\mathrm{NS}$ \\
Protein S, \% & $75 \pm 29$ & $72 \pm 19$ & $75 \pm 33$ & $\mathrm{NS}$ \\
Fibrinogen, mg/dl & $591.80 \pm 190.10$ & $473.40 \pm 142.50$ & $470.20 \pm 100.80$ & $\mathrm{p}<0.05$ \\
D-dimer, $\mu \mathrm{g} / \mathrm{dl}$ & $0.42 \pm 0.13$ & $0.52 \pm 0.10$ & $0.66 \pm 0.15$ & $\mathrm{p}<0.05$ \\
Factor V, \% & $36 \pm 11$ & $42 \pm 23$ & $44 \pm 17$ & $\mathrm{NS}$ \\
Factor VII, \% & $84 \pm 27$ & $82 \pm 24$ & $84 \pm 29$ & $\mathrm{NS}$ \\
Factor VIII, \% & $91 \pm 17$ & $87 \pm 17$ & $90 \pm 14$ & $\mathrm{NS}$ \\
VWF, \% & $93 \pm 42$ & $96 \pm 41$ & $101 \pm 43$ & $\mathrm{p}<0.05$ \\
Factor IX, \% & $62 \pm 20$ & $58 \pm 14$ & $59 \pm 21$ & $\mathrm{NS}$ \\
Factor X, \% & $127 \pm 40$ & $122 \pm 36$ & $114 \pm 41$ & $\mathrm{NS}$ \\
\hline
\end{tabular}

A1 = First value; A2 = 2 h; A3 = 4h; NS = not significant.
$0.05)$ at $4 \mathrm{~h}$ than at the beginning of dialysis. The other hemostatic values showed no significant difference before and during dialysis.

After DDAVP administration, bleeding time and PAI-1 levels were significantly lower $(\mathrm{p}<0.001)$, but aPTT $(p<0.01)$ and tPA $(p<0.05)$ levels increased significantly. Factor VIII and VWF levels increased significantly ( $p<0.05$ and $p<0.01$, respectively) at $4 \mathrm{~h}$ of dialysis (table 3 ). Other parameters showed no difference following DDAVP administration at $4 \mathrm{~h}$ of dialysis.
For the final step of the study, bleeding time was shorter $(p<0.001)$, aPTT levels decreased $(p<0.01)$, tPA values $(\mathrm{p}<0.001)$, factor V $(\mathrm{p}<0.001)$, factor VIII $(\mathrm{p}<$ $0.001)$, VWF $(p<0.001)$, factor IX $(p<0.01)$ and VWF $(p<0.001)$ levels significantly increased (table 3$)$. On the other hand, the protein C level $(\mathrm{p}<0.01)$ and ECLT $(\mathrm{p}<$ 0.001 ) decreased significantly. The other parameters did not change significantly $4 \mathrm{~h}$ later. 


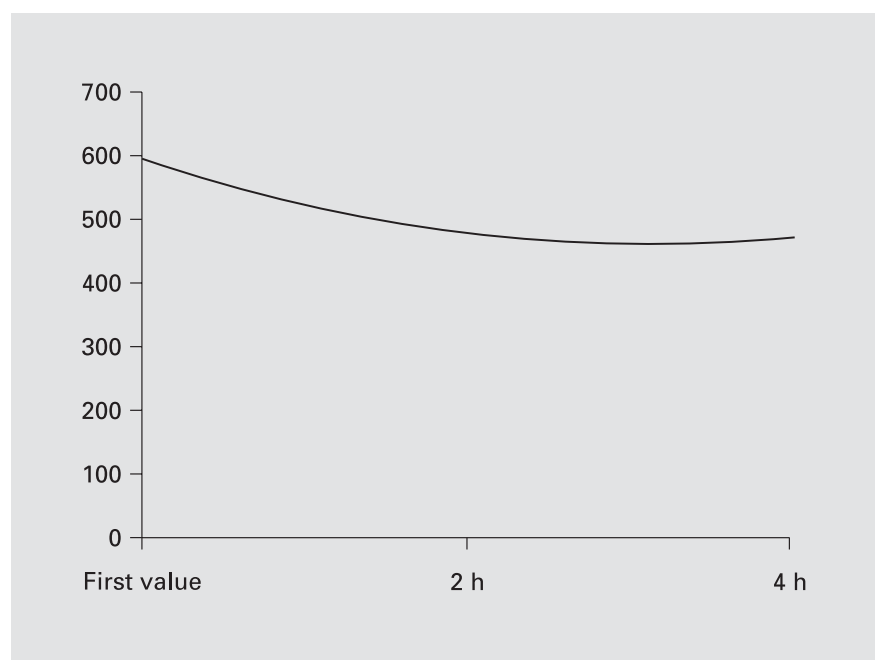

Fig. 3. Fibrinogen levels of the patient group during hemodialysis.

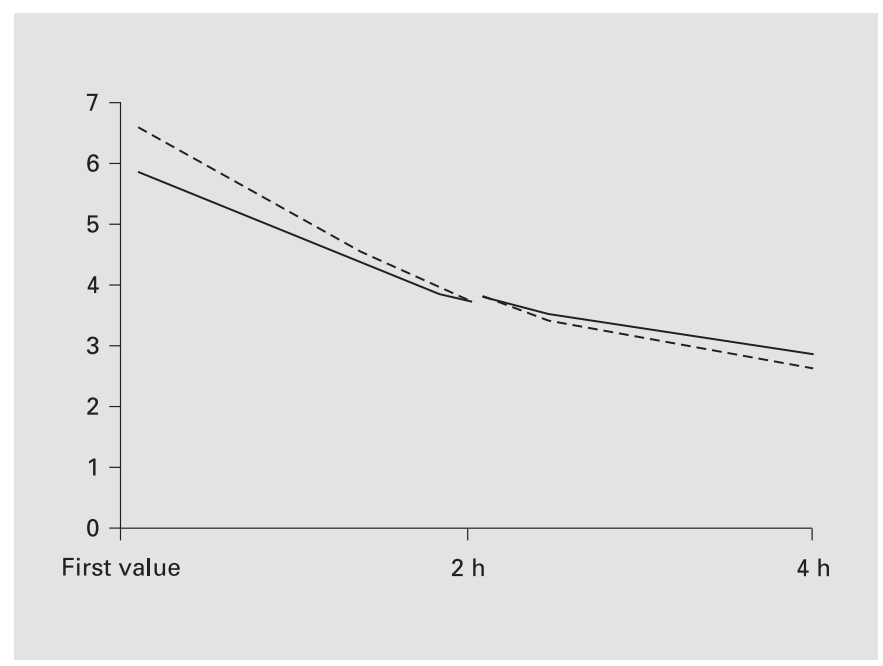

Fig. 4. Bleeding time (min) of the patient group after DDAVP during hemodialysis (interrupted line) and in the interval between hemodialysis sessions (solid line).

Table 3. Hematologic findings in patients with CRF during dialysis and in the interval between dialysis sessions after DDAVP nasal administration

\begin{tabular}{|c|c|c|c|c|c|c|c|c|}
\hline & A1d & $\mathrm{A} 2 \mathrm{~d}$ & A3d & Alde & A2 de & A3de & $\begin{array}{l}\text { A1d } \\
\text { A3d }\end{array}$ & $\begin{array}{l}\text { A1de } \\
\text { A3de }\end{array}$ \\
\hline Bleeding time, $\min$ & $6.60 \pm 2.41$ & $3.78 \pm 1.51$ & $2.64 \pm 1.39$ & $5.85 \pm 1.95$ & $3.71 \pm 1.14$ & $2.82 \pm 1.30$ & $\mathrm{p}<0.001$ & $\mathrm{p}<0.001$ \\
\hline Platelets $/ \mathrm{min}$ & $2.1 \pm 0.8$ & $2.3 \pm 0.7$ & $2.1 \pm 0.7$ & $2.0 \pm 0.7$ & $1.9 \pm 0.7$ & $2.0 \pm 0.7$ & NS & NS \\
\hline PT, s & $13.45 \pm 1.00$ & $14.18 \pm 1.51$ & $14.00 \pm 0.98$ & $13.40 \pm 0.63$ & $13.03 \pm 0.96$ & $13.01 \pm 1.12$ & NS & NS \\
\hline aPTT, s & $34.20 \pm 4.61$ & $92.23 \pm 38.13$ & $95.62 \pm 32.17$ & $30.71 \pm 4.56$ & $30.20 \pm 5.77$ & $28.50 \pm 5.55$ & $\mathrm{p}<0.01$ & $\mathrm{p}<0.01$ \\
\hline $\mathrm{tPA}, \mathrm{ng} / \mathrm{ml}$ & $12.39 \pm 4.42$ & $17.85 \pm 7.40$ & $17.64 \pm 8.24$ & $10.03 \pm 4.39$ & $15.53 \pm 6.15$ & $19.53 \pm 10.98$ & $\mathrm{p}<0.05$ & $\mathrm{p}<0.001$ \\
\hline PAI-1, ng/ml & $34.78 \pm 3.68$ & $20.42 \pm 4.48$ & $15.00 \pm 4.44$ & $35.57 \pm 5.18$ & $28.57 \pm 9.10$ & $23.92 \pm 11.33$ & $\mathrm{p}<0.001$ & $\mathrm{p}<0.01$ \\
\hline ECLT, min & $287.50 \pm 52.00$ & $181.78 \pm 55.00$ & $161.00 \pm 50.65$ & $225.35 \pm 44.84$ & $195.00 \pm 47.85$ & $162.85 \pm 41.00$ & $\mathrm{NS}$ & $\mathrm{p}<0.001$ \\
\hline Protein C, IU/ml & $1.21 \pm 0.35$ & $1.02 \pm 0.35$ & $0.87 \pm 0.23$ & $1.14 \pm 0.36$ & $0.83 \pm 0.30$ & $0.71 \pm 0.30$ & NS & $\mathrm{p}<0.01$ \\
\hline Protein S, \% & $60 \pm 29$ & $68 \pm 41$ & $67 \pm 38$ & $87 \pm 27$ & $86 \pm 33$ & $81 \pm 32$ & NS & NS \\
\hline Fibrinogen, mg/dl & $624.50 \pm 100.70$ & $624.80 \pm 154.30$ & $541.60 \pm 152.00$ & $626.20 \pm 200.00$ & $573.40 \pm 262.68$ & $398.60 \pm 164.30$ & NS & $\mathrm{p}<0.01$ \\
\hline D-dimer, $\mu \mathrm{g} / \mathrm{dl}$ & $0.42 \pm 0.18$ & $0.49 \pm 0.15$ & $0.65 \pm 0.11$ & $0.42 \pm 0.15$ & $0.39 \pm 0.10$ & NS & NS & NS \\
\hline Factor V, \% & $40 \pm 18$ & $41 \pm 12$ & $44 \pm 15$ & $36 \pm 15$ & $51 \pm 21$ & $52 \pm 21$ & NS & $\mathrm{p}<0.001$ \\
\hline Factor VII, \% & $91 \pm 47$ & $84 \pm 21$ & $86 \pm 19$ & $98 \pm 34$ & $107 \pm 45$ & $186 \pm 26$ & NS & NS \\
\hline Factor VIII, \% & $82 \pm 24$ & $123 \pm 81$ & $146 \pm 37$ & $71 \pm 12$ & $134 \pm 46$ & $140 \pm 27$ & $\mathrm{p}<0.05$ & $\mathrm{p}<0.001$ \\
\hline VWF, $\%$ & $86 \pm 41$ & $107 \pm 12$ & $128 \pm 15$ & $88 \pm 37$ & $104 \pm 44$ & $131 \pm 45$ & $\mathrm{p}<0.01$ & $\mathrm{p}<0.001$ \\
\hline Factor IX, \% & $53 \pm 19$ & $68 \pm 21$ & $69 \pm 26$ & $62 \pm 25$ & $77 \pm 33$ & $72 \pm 30$ & NS & $\mathrm{p}<0.01$ \\
\hline Factor X, \% & $116 \pm 41$ & $112 \pm 34$ & $117 \pm 33$ & $119 \pm 29$ & $110 \pm 30$ & $118 \pm 32$ & NS & NS \\
\hline
\end{tabular}

A1d = First value during hemodialysis; A2d = at $2 \mathrm{~h}$ during dialysis after DDAVP; A3d = at $4 \mathrm{~h}$ during dialysis after DDAVP; A1de $=$ first value in the interval between dialysis sessions; A2de $=2 \mathrm{~h}$ after a dialysis session (interval); A3de $=4 \mathrm{~h}$ after a dialysis session (interval). 


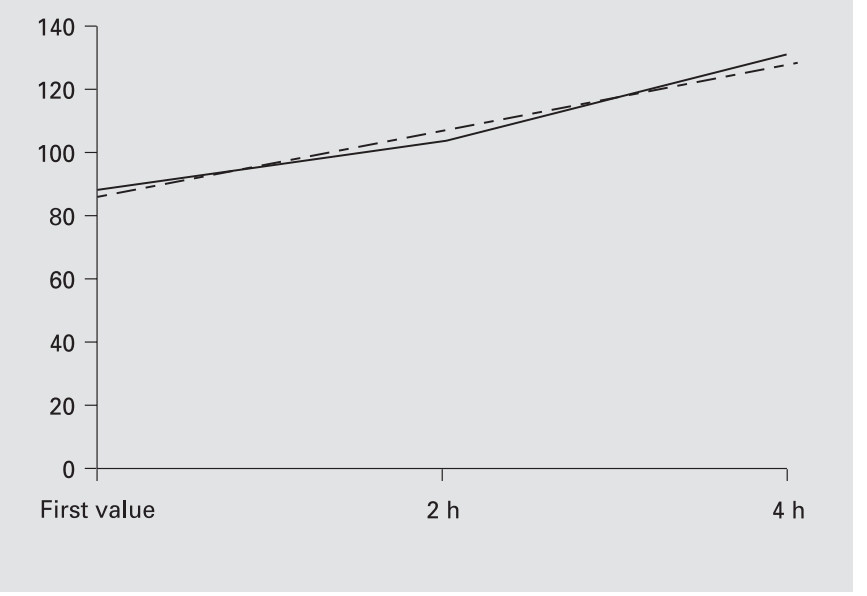

Fig. 5. VWF levels (\%) of the patient group after DDAVP during hemodialysis (interrupted line) and in the interval between hemodialysis sessions (solid line).

\section{Discussion}

In patients with CRF, hemostatic disorders such as bleeding diathesis and hypercoagulability may occur [9], probably due to an increase in prostacyclin levels compared to thromboxane $\mathrm{A}_{2}$, aggregation and adhesion deficiencies of platelets as it has been shown that platelet count and factor VIII and VWF levels in CRF patients were lower than those of healthy people $[10,11]$. In this study, platelet counts were similarly lower, and bleeding time longer in CRF patients than in healthy controls probably due to uremia-related decreased platelet counts and functional alterations in uremic patients [12]. Reduced platelet counts were not below the normal range and therefore could not explain the prolonged bleeding time. It is possible that the decreased platelet count in CRF patients compared to controls might be due to the use of heparin administered during dialysis as previously reported by Charvat et al. [13]. Also of importance is the decreased level of factor $\mathrm{V}$ released from platelets in the patient group, which may be due directly to decreased platelet count and dysfunctional platelet.

Increased levels of fibrinogen in patients may be evidence of suppression of fibrinolysis due to uremic retention [14]. Although PAI-1 level was lower in patients with CRF than in controls, this decrease was not considered to be significant $(p>0.05)$. The other fibrinolytic activity parameters (tPA and D-dimer levels) did not show any difference between patient and control groups.

Decreased bleeding time after $4 \mathrm{~h}$ of hemodialysis indicated the positive effect of dialysis on platelet functions $[15,16]$. Also, aPTT was longer due to heparin administration as expected. The fibrinogen level decreased significantly at $4 \mathrm{~h}$ of dialysis probably due to an increment of tPA by hemodialysis or the aggregation of fibrinogen on the dialysis membrane [8]. The increment of tPA and D-dimer and the decrease of PAI-1 were thought to be due to the increase in fibrinolysis. The level of VWF at $4 \mathrm{~h}$ of hemodialysis was higher than the initial level due to secretion of VWF from endothelium and activated platelets $[17,18]$, which resulted from endothelial damage and normalization of platelet functions during dialysis. We did not observe any difference in the other hemostatic parameters of blood.

After the administration of DDAVP to the patients at the beginning of hemodialysis, bleeding time shortened as previously reported $[6,9,12-16]$. The shortening of bleeding time with DDAVP might be related to the effect of DDAVP on platelet function, serotonin release, thromboxane $\mathrm{A}_{2}$ and VWF release, factor VIII ristocetin cofactor activity, and factor VIII-c activity [2, 5, 6, 19, 20]. Although it has been shown that hemodialysis does not affect factor VIII level [4], apparently with administration of DDAVP, factor VIII level increased as previously noted $[4,6]$.

The increment of tPA at $4 \mathrm{~h}$ during dialysis was much higher with than without DDAVP administration. These results are in concordance with the studies by Takahashi and Levi [7, 8], which showed that DDAVP raised tPA level. In CRF, this effect is important in the reduction of thromboembolic incidents due to a decrease in fibrinolysis. Other parameters did not show significant changes after the administration of DDAVP during hemodialysis.

Bleeding time and aPTT were also decreased with the administration of DDAVP in the intervals between dialysis sessions. These results paralleled the increment of factor VIII, factor V, factor IX and VWF after DDAVP administration in the interval between dialysis sessions. The levels of PAI-1 and fibrinogen decreased while those of tPA and D-dimer increased. Both ECLT and protein $C$ levels were decreased after DDAVP. These results are in agreement with previous studies [4, 7, 8, 21, 22] and these findings may suggest that DDAVP may also increase fibrinolysis in the intervals between dialysis sessions. 


\section{Conclusion}

Patients with CRF have a tendency to bleed more during hemodialysis due to the use of heparin. Bleeding can be controlled with the administration of DDAVP, which shortens bleeding time, increases VWF, factor VIII, factor $\mathrm{V}$ and factor IX, despite the increasing effect of DDAVP on fibrinolysis. No adverse effects were observed by the nasal application of DDAVP.

\section{References}

1 Deane FM: Disorders of blood coagulation; in Wyngoarden JB, Smith LH, Bennett JC, Philadelphia WB (eds): Cecil Textbook of Medicine. London, Saunders, 1992, pp 1078-1079.

2 Eberst ME, Berkowitz LR: Homeostasis in renal disease: Pathophysiology and management. Am J Med 1994;96:168-179.

3 Lindsay RM, Moorthy AV, Koens F, Linton AL: Platelet function in dialyzed and non-dialyzed patients with chronic renal failure. Clin Nephrol 1975;4:52-57.

4 Mannucci PM: Desmopressin: A non-transfusional form of treatment for congenital and acquired bleeding disorders. Blood 1988;72: 1449-1455.

5 Rydzewski A, Rowinski M, Mysliwiec M: Shortening of bleeding time after intranasal administration of 1-deamino-8- $D$-arginine vasopressin to patients with chronic uremia. Folia Haematol Int Mag Klin Morphol Blutforsch 1986;113:823-830.

6 Aunsholt NA, Schmidt EB, Stoffersen E: DDAVP lowers protein $\mathrm{C}$ activity in uremics. Nephron 1989;53:6-8.

7 Takahashi H, Tatewaki W, Wada K, Niwano $\mathrm{H}$, Hanano M, Shibata A: Plasmin generation and fibrin(ogen)olysis following DDAVP infusion. Am J Hematol 1991;36:255-258.
8 Levi M, ten Cate JM, Dooijewaard G, Sturk A, Brommer EJ, Agnelli G: DDAVP induces systemic release of urokinase-type plasminogen activator. Thromb Haemost 1989;62:686689.

9 Woo KT, Wei SS, Lee EJ, Lau YK, Lim CH: Effects of hemodialysis and peritoneal dialysis on antithrombin III and platelets. Nephron 1985;40:25-28.

10 Livio M, Benigni A, Remuzzi G: Coagulation abnormalities in uremia. Semin Nephrol 1985; 5:82-90.

11 Remuzzi G, Benigni A, Dodesini P, Schieppati A, Livio M, De Gaetano G, Day SS, Smith WL, Pinca E, Patrignani P, Patrono C: Reduced platelet thromboxane formation in uremia: Evidence for a functional cyclooxygenase defect. J Clin Invest 1983;71:762-768.

12 Lazarus JM, Hakim RM: Medical aspects of hemodialysis; in Brenner BM, Rector FC Jr (eds): The Kidney, ed 4. Philadelphia, Saunders, 1991, pp 2248-2249.

13 Charvat J, Konig J, Blaha J: Is heparin responsible for enhanced platelet aggregation after hemodialysis? Nephron 1986;44:89-91.

14 Joseph WB, Rector FC Jr (eds): The Kidney, ed 4. Philadelphia, Saunders, 1991, pp 2027 2029.

15 Remuzzi G, Pusineri F: Coagulation defect in uremia. Kidney Int 1988;33(suppl 24):S13S17.
16 Di Minno G, Martinez J, McKean ML, De La Rosa J, Burke JF, Murphy S: Platelet dysfunction in uremia: Multifaceted defect partially corrected by dialysis. Am J Med 1985;79:552559.

17 Bockenstedt P, Greenberg JM, Handin RI: Structural basis of von Willebrand factor binding to platelet glycoprotein Ib and collagen: Effects of disulfide reduction and limited proteolysis of polymeric von Willebrand factor. J Clin Invest 1986;77:743-749.

18 Parker RI, Gralnick HR: Identification of platelet glycoprotein IIb-IIIa as the major binding site for released platelet von Willebrand factor. Blood 1986;68:732-736.

19 Horstman LL, Valle Riestra BJ, Jy W, Wang F, Mao W, Ahn YS: DDAVP acts on platelets to generate platelet microparticles and enhanced procoagulant activity. Thromb Res 1995; 79:163-174.

20 Chen KS, Huang CC, Leu ML, Deng P, Lo SK: Hemostatic and fibrinolytic response to desmopressin in uremic patients. Blood Purif 1997; 15:84-91.

21 Couch P, Stumpf JL: Management of uremic bleeding. Clin Pharm 1990;9:673-681.

22 Malyszko J, Pietraszek MH, Azzadin A, Buczko W, Mysliwiec M: DDAVP induces decrease in platelet serotonin content in uremia. Thromb Haemost 1989;30:537-537. 